С.Г. Сукиасян

\title{
ПСИХОПАТОЛОГИЯ КАК МОДЕЛЬ ПОНИМАНИЯ ПРИРОДЫ ЧЕЛОВЕКА И ПСИХИКИ
}

\begin{abstract}
Аннотация. Предмет настоящего исследования является категория психопатологии как аспект понимания человеческой природы и психики в контексте их возникновения и развития. Автором проведён анализ наиболее известных моделей, так или иначе объясняющих формы поведения человека. Многообразие этих подходов автор рассматривает как некий континуум научной мысли, на одном полюсе которого биологическая модель, а на другом - социокультурная. Представлен анализ наиболее известных моделей психического: биологическая, бихевиоральная, психодинамическая, когнитивная, экзистенциально-гуманистическая, социокультурная. Работа теоретическая и основана на анализе категориальных понятий и подходов, принятых в психологии и психиатрии. В статье представлен оригинальный подход автора к пониманию природы и психики человека - психопатологический. Автор предполагает, что понять человека, его природу можно через понимание его аномального поведения, то есть проявляемой психопатологии, опираясь на комплексный учёт биологических, психологических, сочиокультурных аспектов человеческой природы. Представлен собственный подход к концепции "предрасположенность-стресс», рассматривающий предрасположенность как проявление в силу непонятных пока причин архаичных механизмов функционирования психики, присущих человеку на более ранних стадиях его развития. Нормальность и анормальность поведения человека анализируется в контексте проявлений некоторых психопатологических расстройств (шизофрении, аутизма, агрессивности, суицидальности).

Ключевые слова: психопатология, модели психического, биологическая модель, бихевиоральная модель, психодинамическая модель, когнитивная модель, экзистенциально-гуманистическая модель, социокультурная модель, предрасположенность-стресс, психическое здоровье.

Review. The subject of the present research is the category of psychopathology as an aspect of understanding human nature and mind from the point of view of their origin and development. The author of the article has analyzed the most famous models of human behavior. Variety of approaches is viewed as a continuum of scientific ideas consisting of biological and socio-cultural models. Most famous models of psyche and mind (biological, behavioral, psychodynamic, cognitive, existential-humanistic, socio-cultural) are investigated. This is a theoretical research and it is based on the analysis of categorical concepts and approaches used in psychology and psychiatry. The author's original (psychopathological) approach to understanding human nature is presented. It is suggested that understanding of human nature is possible through analyzing his abnormal behavior (manifested psychopathology) based on a comprehensive consideration of biological, psychological and socio-cultural aspects of human nature. The author offers his own approach to the "disposition-stress» concept and views the predisposition as a manifestation (due to unexplained reasons) of archaic mental mechanisms attributable to the earlier stage of his development. Normal and abnormal human behavior in terms of the manifestations of certain psychopathological disorders (schizophrenia, autism, aggression, suicidality) is analyzed. Key words: theory of mind, biological model, behavioral model, psychodynamic model, cognitive model, existentialhumanistic model, psychopathology, socio-cultural model, predisposition - stress, mental health.
\end{abstract}

H еобходимость понимания природы человека и объяснения его нормального и патологического поведения диктует необходимость изучения причин различных поведенческих отклонений у людей, их ненормального функционирования, которые, в конце концов, носят адаптативный характер, и могут привести к психической патологии. Поведение человека формируется под влиянием самых различных факторов: биологических, социальных, психологических, приобретённых и врождённых. Именно поведение человека даёт нам «материал» для рассуждений о природе человека, о происхождении его психики и формах и механизмах психических отклонений. 
Каждый человек приходит в этот мир с определёнными биологическими задатками, предопределёнными его генотипом. Этот биологический механизм предопределяет (конечно, не абсолютно) тот жизненный путь, по которому пройдёт каждый из нас. Абсолютизм здесь исключён, поскольку есть другой, совершенно уникальный, человеческий механизм, предопределяющий и обеспечивающий жизнедеятельность человека. Этот механизм очень специфический, сугубо человеческий, и действует он в особенном человеческом обществе, которое формирует каждого из нас на основе генотипа через влияние социальных институтов - семья, школа, обстоятельства и т.д. Важно заметить, что это особенное общество в своём развитии выработало определённый генотип (совокупность биологических свойств). Взаимоотношения генотипа с фенотипом (совокупностью внешних и внутренних признаков организма, приобретённых в результате онтогенетического развития), формируют личность и поведение каждого из нас. Взаимоотношения между биологическими и социальными корнями человека могут стать причиной возникновения отклонений в поведении, причиной психических расстройств. Ещё А.Н. Леонтьев отмечал, что проблема биологического и социального имеет для научной психологии решающее значение [1].

Столкновение этих радикалов часто приводит к патологии, конфликтам, что, в свою очередь, чревато формированием аномальных форм поведения. Естественно, что возникает вопрос, как это происходит? Почему возникают те или иные формы проявлений, которые могут восприниматься и трактоваться или как нормальные, или как патологические? Если это реакции имеют адаптативный характер, как утверждают «эволюционисты», то почему они приводят к дезадаптации и конфликту со средой?

Необходимость объяснения причин, которые приводят к возникновению патологических форм поведения и, следовательно, патологических проявлений психики, способствовала появлению различных подходов и моделей (парадигм) [2], так или иначе отражающие исходные посылки авторов, и способствующие дальнейшему развитию данной проблемы [3]. Многообразие этих подходов можно рассматривать как некий континуум научной мысли, на одном полюсе которого биологическая модель, а на другом - социокультурная. Биологическая модель акцентирует в человеческом пове- дении физические процессы. Полярная, социокультурная модель подчёркивает влияние общества и культуры на индивидуальное поведение. Каждая модель по-своему правильна, исходит из конкретных посылок и понятий, но обязательно вступает в конфликт с другой моделью, опирающейся на совершенно другие, но также конкретные и адекватные посылки и понятия. Каждая модель ориентирует исследователей на какой-то один аспект человеческого функционирования и ни одна не может объяснить все аспекты патологии, более того, не пытается понять, как и когда зародились эти формы поведения, являющиеся аномальными.

Биологическая модель. Сторонники биологического направления рассматривают патологическое поведение как болезнь, вызванную аномальным функционированием организма в целом или отдельных его частей. Аномальное поведение они обуславливают анатомическими дефектами головного мозга, дисфункцией нейротрансмиттеров, нарушениями секреции тех или иных гормонов, нарушениями белкового обмена [4; 5; 6; 7]. При этом многие исследователи исходят из того, что подобные нарушения и дисфункции во многих случаях носят наследственный характер [8].

Современная наука дала возможность показать, что в основе психической деятельности человека лежат определённые биохимические и биоэлектрические процессы [9; 10; 11; 12]. Мысли, эмоции и поведение человека имеют биологическую основу. И с этим никто не спорит. Но биологическая модель в основном опирается на результаты и данные биологических экспериментальных исследований, проводимых на животных, и трансполированных на человека, что вносит определённую долю ошибки, отклонения, а также волюнтаризма и спекуляции. Безусловно, нельзя ставить знак равенства между психическим расстройством, вызванным лекарственным или другим воздействием у животных, и истинным расстройством, наблюдаемым у человека [13].

Бихевиоральная модель исследует психическую деятельность и её отклонения на основе изучения поведения человека. Сторонники данной модели считают, что поведение человека есть то, что диктует ему его психика. Следовательно, объяснив поведение, мы можем понять психику. Действия человека, как считают бихевиористы, обусловлены главным образом жизненным опытом. Поэтому, чтобы объяснить аномальное поведение, следует изучить процесс научения девиантному 
поведению в прошлом, и понять, благодаря каким обстоятельствам это поведение сохранилось в настоящем. Многие выученные поведенческие реакции помогают людям справляться с повседневными трудностями и вести продуктивную жизнь. Аналогичным образом происходит усвоение аномального поведения, многих психопатологических симптомов $[14 ; 15]$.

Психодинамическая модель акцентирует своё внимание на исследовании глубинных бессознательных процессов и конфликтов. В отличие от «биологов» и бихевиористов сторонники психодинамической модели считают, что все мы, образно говоря, родом из детства. И любое поведение, в том числе и патологическое, уже в зрелом возрасте является результатом не разрешённых в детстве конфликтов, которые, в свою очередь, возникают в результате одновременного существования противоречивых, конфликтных сексуальных и агрессивных желаний. Конфликты приводят к развитию патологических проявлений. И поскольку эти конфликты не осознаются, то человек, подвергшийся травме, не понимает причину этих проявлений. Последние усиливаются, усугубляя страдания человека. Но аномальное поведение формируется только в тех случаях, когда психологический конфликт становится избыточным. Корни аномального и нормального функционирования одни и те же, и они уходят в ранние взаимоотношения между родителями и ребёнком.

Когнитивная модель исходит из того, что в основе поведения, мышления и эмоций человека лежат познавательные (когнитивные) процессы. Следовательно, аномальное функционирование можно понять, изучая познавательную способность. Когнитивная модель опирается на самый уникальный и самый «человеческий» из человеческих процессов - мышление, благодаря чему человек есть то, что он есть сегодня на пути своей социализации со своими достижениями и специфическими проблемами. Она считает, что нарушения, отклонения, алогичность в мышлении могут быть причиной аномального функционирования, многих видов когнитивных проблем. К примеру, люди могут придерживаться определённых установок в отношении кого-то или чего-то, которые вызывают беспокойство и не соответствуют действительности или не являются точными [16; 17]. Как возможная причина аномального функционирования рассматривается алогичное мышление $[18 ; 19]$.
Экзистенциально-гуманистическая опытная модель проблемы человека рассматривает в свете таких философских вопросов, как самосознание, ценности, смысл и выбор. Экзистенциализм и гуманизм - это два совершенно разных философских подхода, имеющих один общий аспект - подчёркнутое внимание к проблемам человеческого существования. Гуманистическая модель исходит из того, что все люди изначально, то есть врождённо, «от Бога» склонны к дружбе, сотрудничеству и созиданию. И всю свою жизнь они стремятся к реализации своего потенциала добра, но на этом пути им следует преодолеть некоторые свои недостатки. Экзистенциальная модель предполагает, что каждый человек должен иметь точное представление о самом себе и жить содержательной «аутентичной» жизнью, что позволяет ему адекватно и полноценно адаптироваться в среде. Экзистенциалисты считают, что человек от рождения обладает полной свободой выбора жизненных ценностей и пути. Его выбор, найти смысл в жизни и жить полноценной жизнью, или уйти от ответственности и выбора, стать слабым и беспомощным, и жить пустой, неаутентичной жизнью. Это уже чревато возникновением психической патологии в виде тех или иных психопатологических симптомов.

В отличие от отмеченных нами моделей, экзистенциально-гуманистическая модель затрагивает аспект психологической жизни, который другие модели игнорирует. Она исходит из того, что у психически больных людей явно отсутствуют такие важные для эффективного функционирования факторы, как принятие себя, личностные ценности, личностный смысл и личностный выбор. Гуманистическая психология считает, что любые проблемы, тормозящие процесс самоактуализации личности, приводят к аномальному поведению, которое есть результат уклонения от жизненных обязанностей [20].

Социокультурная модель аномальное поведение человека понимает и объясняет в контексте взаимодействия социальных и культурных аспектов деятельности с личностью [13]. Тем самым аномальность человеческого поведения она выводит из социального контекста бытия человека, исходя из того, что это поведение формируется в результате и посредством социальных взаимодействий. Толкования сторонников социокультурной модели опираются на такие понятия, как семейная структура и коммуникации, социальные сети, общественные условия и общественные ярлыки и 
роли. Семьи бывают очень разными, и каждая из них имеет свою систему отношений и свои правила, которые формируют человека, который в другой системе отношений может проявить себя аномально с точки зрения члена другой семьи.

Исходя из понимания семьи, как системы, в которой взаимодействующие части (то есть члены семьи) связаны друг с другом устойчивыми отношениями и руководствуются правилами, уникальными для каждой системы [21], сторонники данной модели считают, что особенности структуры и общения некоторых семей вынуждают отдельных членов вести себя в манере, которую в других случаях можно признать аномальной. Модель предполагает, что существуют так называемые дисфункциональные семьи, которые предрасположены к аномальному функционированию отдельных её членов [22; 23]. Это так называемые «связанные семьи», в которых членов семьи отличает повышенная общность действий, мыслей и чувств, или же «разобщённые семьи», где каждый живёт «сам по себе». Лишённые социальной поддержки, близости и тепла, дети из таких семей часто создают проблемы себе и окружающим, обнаруживая порой неадекватное поведение. Они часто дают стрессовые и аффективные реакции, их депрессии имеют длительное течение, по сравнению с теми, кто имеет надежную семейную поддержку и соучастие друзей $[24 ; 25 ; 26 ; 27 ; 28 ; 29 ; 30]$. Источником специфических стрессов может стать широкий спектр социальных условий, повышающих вероятность аномального функционирования [13]. Психическая аномалия с позиций данной модели определяется качеством и характером социальных и профессиональных отношений членов каждой семьи с другими людьми. Дисфункциональность этих семей, с позиции данной модели, обусловлена также более низким социально-экономическим уровнем [31], что предполагает более высокий уровень преступности, безработицы, неудовлетворённость жилищными условиями, бездомность, низкий уровень медицинской помощи и образования, что в совокупности оказывают сильное давление на членов этих групп [32; 33; 34]. Не исключается, что психические нарушения, являются не следствием, а причиной низкого социально-экономического уровня людей.

Среди факторов, значимых для социокультурной модели в развитии психической патологии, отмечаются расовые и гендерные факторы: женщины чаще страдают тревожными и депрессивными расстройствами; необычно высокий уровень тревожных расстройств выявляется среди афроамериканцев, среди белых лиц пожилого возраста $[35 ; 36 ; 37 ; 38 ; 39 ; 40]$. Хотя эти различия могут быть вызваны комбинацией многих факторов, расовые и сексуальные предрассудки и те проблемы, которые они порождают, скорее всего, напрямую способствуют аномальным паттернам напряжения, несчастья, низкой самооценки и ухода от жизни [41; 42]. Немаловажна в аномальном функционировании и роль стигмы.

Таким образом, основные современные модели каждая по-своему трактует те или иные аспекты человеческого функционирования. С нашей точки зрения, понять человека, его природу через понимание его аномального поведения (то есть, психопатологии), можно только учитывая и биологические, и психологические, и социокультурные аспекты человеческой проблемы, а не только какой-то один из них.

Всё, что происходит в природе, имеет свои причины и следствия. Другое дело, что мы не всегда их видим и адекватно понимаем. И всё, что происходит в природе, оно заложено в некоей программе, другое дело, что программа срабатывает не всегда. В контексте нашей идеи, понятно, почему многие исследователи (и клиницисты в том числе) придерживаются концепции «предрасположенностьстресс»: люди должны сначала обладать определённой биологической, психологической или социокультурной предрасположенностью к тому, что у них проявляется, в том числе и к психическому расстройству. Но проявляется это лишь после непосредственного воздействия того или иного фактора (стресса). Но что такое предрасположенность? Это предрасположенность в буквальном смысле данного слова - как навык, готовность, склонность или тенденция действовать определённым образом, как повышенная вероятность развития заболевания в силу каких-то особенностей организма или среды? Или же предрасположенность понимать как проявление в силу непонятных пока причин архаичных механизмов функционирования психики, присущих человеку на более ранних стадиях его развития? При втором подходе имеют место не какие-то факторы риска, известные каждому психиатру, а проявление адекватных в исторических эпохах форм психического функционирования, но уже неадекватных в современных условиях под влиянием факторов внешней и внутренней среды. Ещё в 70-х гг. прошлого века видный советский учёный-историк Б.Ф. Порш- 
нев [43], исследования которого не всегда «соответствовали» советской идеологии и официальной науки, писал, что психически больные люди есть неизбежное, согласно законам генетики, воспроизведение у небольшой части людей отдельных черт предкового вида палеоантропов. Автор имел в виду не широкий комплекс характерных признаков этой предковой формы, а лишь некоторые признаки. Он проводил аналогии с физическими (соматическими) признаками, и в доказательство своих предположений приводил пример людей с очень выраженным и распространенным волосяным покровом при отсутствии всяких других «неандертальских» предковых симптомов; есть люди с другими морфологическими проявлениями (скулы, надбровные валики, большой торс и длинные руки и т.д.). Отдельные предковые признаки проявляются в старости, причём у женщин статистически несколько чаще [41; 42]. Те люди, у которых в сильной форме воспроизводятся некоторые психические черты предковой формы, попадают в категорию психически больных. Это в основной массе неконтактные личности. Они представляют интерес в плане проявляемого ими симптомокомплекса, который, как пишет Б.Ф. Поршнев [43], является лишь «памятником жизни существ, ещё не перешедших в людей». Анализируя поведение «психотиков», автор заключает, что в положении психотика есть нечто генетически напоминающее паразитизм при вполне здоровом теле. В мире животных нет психопатологии. Неврозы у животных могут быть только экспериментальными, то есть в искусственно созданных человеком условиях. В природной обстановке животное-невротик обречено на быструю смерть. Таким образом, чтобы как-то ответить на выше поставленный вопрос, следует определить, а что значит быть психически здоровым. Что включает в себя категория «психически здоровая личность»?

Мы не можем на сегодня дать удовлетворяющие все модели психического дефиниции и представления. В психологической литературе понятие «психическое здоровье» рассматривается как состояние душевного благополучия, характеризующееся отсутствием болезненных психических проявлений и обеспечивающее адекватную условиям окружающей действительности регуляцию поведения и всей многообразной деятельности. Это определение исходит из медицинских и индивидуально-психологических критериев, и не отражает общественную сущность человека.
Почти все психологические теории, так или иначе рассматривающие личность во всех её ипостасях, рассматривают проблему психологического благополучия. Так, Зигмунд Фрейд полагал, что функционирование зрелой личности характеризуется способностью продуктивно работать и поддерживать удовлетворительные межличностные отношения. Способность работать предполагает способность ставить перед собой долговременные отдаленные цели и достигать их, а также справляться с тревогой таким образом, чтобы это не отражалось негативно на поведении. Точно так же, акцент на удовлетворительные социальные отношения предполагает способность наслаждаться широким спектром эмоций без чувства угрозы, привносить созидательные элементы в удовлетворение сексуальных и агрессивных побуждений.

Альберт Бандура придерживается точки зрения, что деятельность человека есть продукт множественного действия событий окружающей среды, поведения человека и свойств его личности, особенно мышления [44]. Самым важным в функционировании человека автор считает способность удовлетворять требованиям жизни, выбирать именно те виды поведения, которые необходимы для достижения цели. Бандура утверждает, что люди, оценивающие сами себя как сильных личностей, ставят перед собой более трудные задачи, затрачивают больше усилий и в результате могут быть более успешными в достижении своих целей.

Абрахам Маслоу нормальной считает ту личность, которая адекватно ставит акценты в выборе и значимости потребностей - от наиболее примитивных (физиологические и потребности безопасности) к наиболее возвышенным потребностям или наиболее «человеческим» (в истине и красоте). К категории нормальных людей А. Маслоу относит тех, кто обладает такими качествами, как эффективное восприятие реальности, потребность в уединении и частной жизни, принятие себя и других [45].

Как следует из выше приведенных ссылок на классиков, в проблеме понимания и дефиниции психического здоровья ключевым остаётся вопрос о критериях оценки последнего. Очевидно, что каким-то одним критерием определить суть проблемы просто невозможно, поэтому наиболее перспективным представляется комплексный подход к оценке психического здоровья человека. А.А. Крылов [46], анализируя отдельные попытки 
охарактеризовать основные проявления здоровой психики с помощью совокупности критериев, приходит к двум общим выводам. Во-первых, наблюдается совершенно очевидный разброс во мнениях авторов в выборе ряда критериев психического здоровья, что, по мнению автора, является свидетельством того, что они наиболее точно характеризуют состояние психического здоровья. Во-вторых, в этих критериях не заложен какойлибо классифицирующий признак, который позволил бы придать им возможную внутреннюю организацию. А.А. Крылов выделяет перечень критериев, позволяющих оценить личность как здоровую или больную, которые он подразделяет на три группы: психические свойства, состояния и процессы. Свойства психически здоровой личности автор представил следующим образом: оптимизм, сосредоточенность, уравновешенность, нравственность (честность, совестливость и др.), адекватный уровень притязания, чувство долга, уверенность в себе, не обидчивость (умение освобождаться от затаённых обид), трудолюбие, независимость, непосредственность (естественность), ответственность, доброжелательность, чувство юмора, терпеливость, самоуважение, самоконтроль. Психические состояния - эмоциональная устойчивость (самообладание), зрелость чувств соответственно возрасту, совладение негативными эмоциями, свободное и естественное проявление чувств и эмоций, способность радоваться, сохранность привычного (оптимального) самочувствия. Психические процессы: максимальное приближение субъективных образов к отражаемым объектам действительности (адекватность психического отражения), адекватное восприятие самого себя, способность концентрации внимания на предмете, удержание информации в памяти, способность к логической обработке информации, критичность мышления, креативность (способность к творчеству, умение пользоваться интеллектом), знание себя, дисциплина ума (управление мыслями). Особое значение среди критериев психического здоровья личности А.А. Крылов придаёт таким факторам, как степень её интегрированности, гармоничности, консолидированности, уравновешенности, духовности, приоритетам гуманистических ценностей (доброта, справедливость), ориентации на саморазвитие, самообогащение. С позиций самоуправления здоровая личность характеризуется выраженной целеустремленностью (обретением смысла жиз- ни), волей, энергичностью, активностью, самоконтролем, адекватной самооценкой.

Опираясь на критерии, выделенные А.А. Крыловым, можно сделать вывод, что психическое здоровье как составной элемент здоровья, включает в себя совокупность психических характеристик, обеспечивающих динамическое равновесие и возможность человеку выполнения социальных функций. Психически здоровый человек адаптирован к социуму и является его активным участником. Следовательно, мы можем сказать, что психическое здоровье, прежде всего, определяется особенностями баланса, гармонии, жизненных сил человека и своеобразия его жизненного пространства.

Наиболее признанной дефиницией психического здоровья является определение, предложенное Всемирной организацией здравоохранения (В03). Она определяет психическое здоровье как состояние благополучия, при котором каждый человек может реализовать свой собственный потенциал, справляться с обычными жизненными стрессами, продуктивно и плодотворно работать, а также вносить вклад в жизнь своего сообщества. В03 выделяет следующие критерии психического здоровья: 1) осознание и чувство непрерывности, постоянства и идентичности своего физического и психического «Я»; 2) чувство постоянства и идентичности переживаний в однотипных ситуациях; 3) критичность к себе и своей собственной психической продукции (деятельности) и её результатам; 4) соответствие психических реакций (адекватность) силе и частоте средовых воздействий, социальным обстоятельствам и ситуациям; 5) способность самоуправления поведением в соответствии с социальными нормами, правилами, законами; 6) способность планировать собственную жизнедеятельность и реализовывать эти планы; 7) способность изменять способ поведения в зависимости от смены жизненных ситуаций и обстоятельств.

Психическое здоровье человека находится под постоянным воздействием среды, в первую очередь, социальной - семьи, работы, досуга, различных организаций и людей и др. Это воздействие может иметь как конструктивный, так и деструктивный характер. Следовательно, любая форма поведения хоть каким-то образом отклоняющаяся от критериев вышеприведенной нормы, представляется как аномальная или патологическая. Она аномальная, потому что психические проявления, направленные на сохранение адаптации, гомеоста- 
за, входят в противоречие с действительностью. В свете выше изложенного любое психическое расстройство (психопатология), есть одно из проявлений адаптации человека в изменяющихся условиях естественной и социальной среды существования. В полной мере это можно отнести и к психопатологическим состояниям, и реакциям, и к нозологиям, в том числе, и к шизофрении, которая сохраняется в ходе генетической и культурной эволюции человека в той или иной форме.

Разумеется, это не случайно. Такая постановка вопроса, с нашей стороны, направлена на поиск решения проблемы, которую можно сформулировать как «являются ли психические расстройства (шизофрения и другие психозы) болезнью или это эволюционно закрепленная форма поведения, гомологичная или аналогичная поведению пациента с психическим расстройством». Это болезнь или архаическая форма поведения человека? Вопрос, конечно, риторический. Шизофрения и все психозы - такие же болезни, как многие другие физические (соматические) болезни, хотя бы потому, что подчиняется многим закономерностям, присущим общей патологии человека, поскольку полностью соответствует критериям «нозоса», наконец, потому, что ограничивает свободу жизни [47].

Но откуда берутся и как возникают психопатологические симптомы психозов (шизофрении)? Почему человек слышит голоса или видит образы? Почему возникает слуховой или зрительный феномен без объективного источника? Может быть они «заложены» в самом психическом? Почему «звучат» мысли у больных и они «доступны» всем? Почему больной шизофренией, может читать и передавать мысли на расстоянии? Почему он говорит о вещах странных, непонятных, нелепых с нашей точки зрения, но вполне адекватных с их позиций? И т.д. и т.п.

Это относится и к аутизму, сущность которого, прежде всего, заключается в нарушениях взаимодействия с окружающим миром, обусловленных дизонтогенезом, задержкой умственного и личностного развития. Жизнь ребёнка смещается на примитивно-регрессивный уровень деятельности (или не выходит из этого уровня), что доставляет ему некоторое удовольствие [48]. Такое понимание аутизма в детстве, как отмечает Г.Т. Красильников [49], цитируя некоторых авторов, не противоречит и осмыслению аутизма как «погружения в себя безотносительно его содержания» (H. Kranz), и пониманию аутизма с позиций нарушения ин- формационного обмена со средой (J. Glatzel). Продуктивная, креативная деятельность ребёнка замещается примитивной, стереотипной деятельностью, что приводит к регрессу на более низкие уровни развития [48]. Но следует заметить, что эту задержку умственного и личностного развития не следует понимать исключительно лишь как онтогенетический процесс, поскольку этот онтогенез повторяет филогенез. Иначе говоря, это возврат к архаическим формам и механизмам. Так, по крайней мере, представляется этот процесс мне.

Современные цитологические и морфологические исследования позволяют предположить, что при эндогенном аутизме происходит блокада информации, обусловленная синаптическими расстройствами между корковыми нейронами. При синдроме Ретта обнаруживаются нарушения, близкие нарушениям указанных структур мозга. При органическом аутизме поражение охватывает иные проводящие пути в центральной нервной системе, что, по-видимому, также способствует блокаде внешней информации; при парааутизме наблюдается не блокада информации, а её недостаточность в связи с обеднением социальной среды. При аутизме в детстве как обособленном расстройстве эндогенного происхождения всегда сочетаются патологический процесс и нейродизонтогенез. Новые данные о физиологическом апоптозе, поэтапных изменениях клеточных популяций нейронов в центральной нервной системе, их особом взаимодействии с областями-мишенями, нуждающимися в наибольшей стимуляции при становлении моторики, речи и других психических функций, помогают понять особую значимость аутистических проявлений в этом процессе. Нарушение информационного поля в связи с аутизмом качественно меняет состояние областей-мишеней, что способствует недоразвитию ребёнка или его остановке в развитии [48].

Представляет интерес и такая форма поведения, как агрессия и аутоагрессия, как эволюционно приобретённая форма поведения. Высокий уровень самоубийств в различных обществах одного этноса позволяет предположить, что на ранних стадиях этногенеза некоторые поведенческие особенности, предрасполагающие к самоубийству, были зафиксированы в генофонде нации. В частности, об этом свидетельствуют исследования одного из самых рассеянных по европейскому континенту этносов угро-финнов, представленных венграми, финнами, карелами, удмуртами, коми [50]. В Центральной 
Европе живут венгры, финны и карелы - на севере, удмурты и коми - на Урале. При этом, этот этнос разделён не только географически, они отличаются многими социальными, экономическими и культурными особенностями. Изоляция отдельных народов друг от друга длится много веков [50; 51; 52].

При анализе психологических особенностей было выявлено, что у лиц с суицидальным поведением наиболее частыми являются такие черты, как затруднённый самоконтроль, склонность к импульсивным поведенческим реакциям, эмоциональное возбуждение, повышенная раздражительность, лёгкость принятия решений, беспечность, эмоциональная незрелость, внутренняя напряжённость, тревога, снижение настроения, пессимистическая оценка перспективы, высокая подозрительность с тенденцией к образованию ситуационно обусловленных бредовых идей отношения, жестокость, злобность, ригидность мышления, некорригируемость установок. Сочетание этих факторов порождает враждебное отношение к окружающему и агрессивность [51; 52; 53; 54]. Су- ициденты угро-финнской национальности отличались от суицидентов русской национальности наличием национального нигилизма (практически не представленного в русской выборке) в форме амбивалентного отношения к своей национальности. Большая часть суицидентов (63\%), внутренне идентифицируя себя с удмуртским этносом и принимая себя в этом качестве, во внешнем, социальном плане старалась не афишировать или даже скрыть национальную принадлежность, поменяв национальность в паспорте. Меньшая часть (37\%) демонстрировала подчёркнуто позитивное отношение к своей национальности, являвшееся, повидимому, отражением самозащитных форм реагирования [55].

Ни одна из выше рассмотренных нами моделей аномального поведения человека, следовательно, моделей развития психопатологической симптоматики не даёт ответов на поставленные нами вопросы. Ответ на эти вопросы даёт метод анализа психопатологии, определяемый нами как психоархеология. Об этом - в следующих работах.

\section{Список литературы:}

1. Леонтьев А.Н. Биологическое и социальное в психике человека // Вопросы психологии. 1960. № 6. С. 23-38.

2. Комер Р. Патопсихология поведения. Нарушения и патологии психики. 4-е международное издание. М.: ПраймЕврознак, 2005. 640 с.

3. Кун Т. Структура научных революций. М.: Прогресс, 1977. 300 с.

4. Ашмарин И.П., Данилова Р.А., Рудько О.И. и др. Долговременное действие пептидных регуляторов: отложенные и инверсные эффекты холецистокинина-4 и -3 // Мед. акад. журн. 2004. № 4(1). С. 4-13.

5. Fibiger H.C., Miller J.J. An anatomical and electrophysiological investigation of the serotonergic projection from the dorsal raphe nucleus to the substantia nigra in the rat // Neuroscience. 1987. № 2. P. 975-987.

6. Kapur S, Remington G. Serotonin-dopamine interaction and its relevance to schizophrenia // Am J Psychiatry. 1996. № 153. P. 466-476.

7. Lieberman J.A., Koreen A.R. Neurochemistry and neuroendocrinology of schizophrenia: a selective review // Schizophr Bull. 1993. № 19. P. 371-429.

8. Gershon E.S., Rieder R.O. Major disorders of mind and brain // Sci Am. 1992. № 267. P. 126-133.

9. Agnati L.F., Zoli M., Stromberg I., Fuxe K. Intercellular communication in the brain: wiring versus volume transmission // Neuroscience. 1995. № 69. P. 711-726.

10. Weinberger D.R., Berman K.F., Chase T.N. Mesocortical dopaminergic function and human cognition // Ann N Y Acad Sci. 1988. № 537. P. 330-338.

11. Wilson C.J., Kawaguchi Y. The origins of two-state spontaneous membrane potential fluctuations of neostriatal spiny neurons // J Neurosci. 1996. № 16. P. 2397-2410.

12. Wong D.F., Wagner H.N., Jr., Tune L.E. et al. Positron emission tomography reveals elevated D2 dopamine receptors in drugnaive schizophrenics // Science. 1986. № 234. P. 1558-1563.

13. Kleinman A., Cohen A. Psychiatry's global challenge // Scientific American. 1997. № 276. P. 86-89.

14. Wolpe J. The promotion of scientific psychotherapy: A long voyage / In J.K. Zeig (Ed.), The evolution of psychotherapy. New York: Brunner / Mazel, 1987. P. 133-148.

15. Wolpe J. From psychoanalytic to behavioral methods in anxiety disorders: A continuing evolution / In J.K. Zeig (Ed.), The evolution of psychotherapy: The third conference. Philadelphia, PA, US: Brunner / Mazel, 1997. P. 107-116.

16. Ellis A. Reason and emotion in psychotherapy. Secaucus, NJ: Lyle Stuart, 1962. 443 p.

17. Ellis A. The basic clinical theory of rational-emotive therapy / In A. Ellis \& R. Grieger (Eds.). Handbook of rational-emotive therapy. New York: Springer Publishing, 1977. P. 3-34.

18. Beck A.T. Depression: Clinical, experimental and theoretical aspects. New York, Hoeber Medical Division, Harper \& Row, 1967. $370 \mathrm{p}$. 
19. Beck A.T. Cognitive approaches to stress. In P.M. Lehrer, R.L. Woolfolk (Eds.), Principles and practice of stress management (2nd ed.). New York: Guilford. 1993. P. 333-372.

20. Fuller R.C. Carl Rogers, Religion, and the Role of Psychology in American Culture // J. Humanistic Psychology. 1982. № 22(4). P. 21-32.

21. Rolland, J.S., Walsh F. Family Therapy: Systems Approaches to Assessment and Treatment / In R.E. Hales, S. Yudofsky, J. Talbott (Eds.) American Psychiatric Press Textbook of Psychiatry. 2nd Edition. Philadelphia: American Psychiatric Press. 1994. P. 1097-1126.

22. Becvar D.S., Becvar R.J. Family therapy: A systemic integration. Boston, MA: Allyn \& Bacon, 1993.400 p.

23. Nichols M. Family therapy: Concepts and methods. New York: Gardner Press, 1984. 609 p.

24. Husaini B.A., Sherkat D.E., Levine R. et al. Race, Gender, and Health Care Service Utilization and Costs among Medicare Elderly with Psychiatric Diagnoses // J Aging Health. 2002. № 14(1). P. 79-95.

25. Jeon H-S., Dunkle R.E. Stress and Depression Among the Oldest-Old: A Longitudinal Analysis // Research on Aging. 2009. № 31. P. 661-687.

26. Mair C.A. Social Ties and Depression: An Intersectional Examination of Black and White Community-Dwelling Older Adults // J. Applied Gerontology. 2010. № 29(6). P. 667-696.

27. Mills T.L., Henretta J.C. Racial, Ethnic, and Sociodemographic Differences in the Level of Psychosocial Distress among Older Americans // Research on Aging. 2001. № 23(2). P. 131-152.

28. Paykel E.S. Life events, Social support and depression // Acta Psychiatrica Scandinavica. 1994. № 89(377). P. 50-58.

29. Ravindran A.V., Matheson K., Griffiths J. et al. Stress, coping, uplifts, and quality of life in subtypes of depression: a conceptual frame and emerging data // J. Affective Disorders. 2002. № 71(1-3). P. 121-130.

30. Sherbourne C.D., Hays R.D., Wells K.B. Personal and psychosocial risk factors for physical and mental health outcomes and course of depression among depressed patients // J. Consulting and Clinical Psychology. 1995. № 63(3). P. 345-355.

31. Dohrenwend B.P., Itzhak L., Shrout P. et al. Socioeconomic Status and Psychiatric Disorders: The Causation-Selection Issue // Science. 1992. № 255. P. 946-952.

32. Ensminger M.E. Welfare and Psychological Distress: A Longitudinal Study of African America Urban Mothers // J. Health and Social Behavior. 1995. № 36(4). P. 346-359.

33. Vostanis P., Grattan E., Cumella S., Winchester C. Psychosocial Functioning of Homeless Children // J. American Academy of Child \& Adolescent Psychiatry. 1997. № 36(7). P. 881-889.

34. Zima B.T., Bussing R., Freeman S. et al. Behavior Problems, Academic Skill Delays and School Failure Among School-Aged Children in Foster Care: Their Relationship to Placement Characteristics // J. Child and Family Studies. 2000. № 9(1). P. 87103.

35. Blazer D.G., Landerman L.R., Hays J.C. et al. Symptoms of depression among community-dwelling elderly African-American and White older adults // Psychological Medicine. 1998. № 28(06). P. 1311-1320.

36. Culbertson F.M. Depression and Gender: An International Review // American Psychologist. 1997. № 52(1). P. 25-31.

37. Kessler R.C., McGonagle K.A., Nelson C.B. et al. Sex and depression in the National Comorbidity Survey. II: Cohort effects // J. Affective Disorders. 1994. № 30. P. 15-26.

38. National Advisory Mental Health Council, 1996: Basic behavioral science research for mental health: perception, attention, learning, and memory // American Psychologist. 1996. № 51(2). P. 133-142.

39. National Advisory Mental Health Council. Basic behavioral science research for mental health: Sociocultural and environmental processes // American Psychologist. 1996. № 51. P. 722-731.

40. Scheid T.L., Brown T.N. A Handbook for the Study of Mental Health: Social Contexts, Theories, and Systems. 2-nd Edition University Cambridge University Press, 2009. 736 p.

41. Sue D.W. A conceptual model for cultural diversity training // J. Counseling \& Development. 1991. № 70. P. 99-105.

42. Sue D.W., Arredondo P., McDavis R.J. Multicultural Counseling Competencies and Standards: A Call to the Profession // J. Counseling \& Development. 1992. № 70. P. 477-486.

43. Поршнев Б.Ф. О начале человеческой истории (Проблемы палеопсихологии). М.: Мысль, 1974. 487 с.

44. Бандура А. Теория социального научения / Пер. с англ. Н.Н. Чубарь. СПб.: Евразия, 2000. 320 с.

45. Маслоу А. Новые рубежи человеческой природы. М.: Смысл, 1999. 425 с.

46. Крылов А.А. Психология: учебник / Под ред. А.А. Крылова, 2007. 752 с.

47. Адо А.Д. и соавт. Патологическая физиология: Учебник для медицинских ВУЗов / А.Д. Адо, М.А. Адо, В.И. Пыцкий, Г.В. Порядин, Ю.А. Владимиров. М.: Триада-Х, 2000. 607 с.

48. Башина В.М. К проблеме раннего детского аутизма // Шизофрения и расстройства шизофренического спектра / Под ред. А.Б. Смулевича. М., 1999. С. 98-108.

49. Красильников Г.Т. Аутизм и аутистический синдром // Журн. невропатол. психиатр. 1996. № 2. С. $105-110$.

50. Х Хабиб О. Суициды среди угро-финнов // Русский медицинский журнал. 1996. Том 4. Bып. 7. (URL: http://www.rmj.ru/ articles_3097.htm\#R5).

51. Положий Б.С. Этно-и социокультуральные аспекты психического здоровья в современной России // Сборник научных трудов «Культуральные и этнические проблемы психического здоровья». М.-Ижевск, 1996. Вып. 1. С. 4-13.

52. Соколова Е.Д. Сравнительное психопатологическое исследование в межрегиональном, транскультуральном и микросоциальном аспектах: Автореф. дисс. докт. мед. наук. М., 1986. 43 с. 


\section{Психология и психотехника 10(85) • 2015}

53. Амбрумова А.Г. Суицидальное поведение как объект комплексного изучения // Сборник научных трудов «Комплексные исследования в суицидологи». М., 1986. С. 7-25.

54. Чухраева А.В. Психологические особенности больных с суицидальными тенденциями //Украинский вестник психоневрологии. 1996. Том 4. № 1(8). С. 123-127.

55. Пчельников Ю.М., Лазебник А.И. Психологическое исследование суицидентов русской и удмуртской национальности // История Сабуровой дачи: Успехи психиатрии, неврологии, нейрохирургии и наркологии. Сборник научных работ Украинского НИИ клинической и экспериментальной неврологии и психиатрии и Харьковской городской клинической психиатрической больницы № 15 (Сабуровой дачи) / Под общ. ред. И.И. Кутько и П.Т. Петрюка. Харьков, 1996. Том 3. С. 314-316.

\section{References (transliteration):}

1. Leont'ev A.N. Biologicheskoe i sotsial'noe v psikhike cheloveka // Voprosy psikhologii. 1960. № 6. S. 23-38.

2. Komer R. Patopsikhologiya povedeniya. Narusheniya i patologii psikhiki. 4-e mezhdunarodnoe izdanie. M.: Praim-Evroznak, 2005. $640 \mathrm{~s}$.

3. Kun T. Struktura nauchnykh revolyutsii. M.: Progress, 1977. $300 \mathrm{~s}$.

4. Ashmarin I.P., Danilova R.A., Rud'ko O.I. i dr. Dolgovremennoe deistvie peptidnykh regulyatorov: otlozhennye i inversnye effekty kholetsistokinina-4 i -3 // Med. akad. zhurn. 2004. № 4(1). S. 4-13.

5. Fibiger H.C., Miller J.J. An anatomical and electrophysiological investigation of the serotonergic projection from the dorsal raphe nucleus to the substantia nigra in the rat // Neuroscience. 1987. № 2. P. 975-987.

6. Kapur S, Remington G. Serotonin-dopamine interaction and its relevance to schizophrenia // Am J Psychiatry. 1996. № 153. P. 466-476.

7. Lieberman J.A., Koreen A.R. Neurochemistry and neuroendocrinology of schizophrenia: a selective review // Schizophr Bull. 1993. № 19. P. 371-429.

8. Gershon E.S., Rieder R.O. Major disorders of mind and brain // Sci Am. 1992. № 267. P. 126-133.

9. Agnati L.F., Zoli M., Stromberg I., Fuxe K. Intercellular communication in the brain: wiring versus volume transmission // Neuroscience. 1995. № 69. P. 711-726.

10. Weinberger D.R., Berman K.F., Chase T.N. Mesocortical dopaminergic function and human cognition // Ann N Y Acad Sci. 1988. № 537. P. 330-338.

11. Wilson C.J., Kawaguchi Y. The origins of two-state spontaneous membrane potential fluctuations of neostriatal spiny neurons // J Neurosci. 1996. № 16. P. 2397-2410.

12. Wong D.F., Wagner H.N., Jr., Tune L.E. et al. Positron emission tomography reveals elevated D2 dopamine receptors in drugnaive schizophrenics // Science. 1986. № 234. P. 1558-1563.

13. Kleinman A., Cohen A. Psychiatry's global challenge // Scientific American. 1997. № 276. P. 86-89.

14. Wolpe J. The promotion of scientific psychotherapy: A long voyage / In J.K. Zeig (Ed.), The evolution of psychotherapy. New York: Brunner / Mazel, 1987. P. 133-148.

15. Wolpe J. From psychoanalytic to behavioral methods in anxiety disorders: A continuing evolution / In J.K. Zeig (Ed.), The evolution of psychotherapy: The third conference. Philadelphia, PA, US: Brunner / Mazel, 1997. P. 107-116.

16. Ellis A. Reason and emotion in psychotherapy. Secaucus, NJ: Lyle Stuart, 1962. 443 p.

17. Ellis A. The basic clinical theory of rational-emotive therapy / In A. Ellis \& R. Grieger (Eds.). Handbook of rational-emotive therapy. New York: Springer Publishing, 1977. P. 3-34.

18. Beck A.T. Depression: Clinical, experimental and theoretical aspects. New York, Hoeber Medical Division, Harper \& Row, 1967. $370 \mathrm{p}$.

19. Beck A.T. Cognitive approaches to stress. In P.M. Lehrer, R.L. Woolfolk (Eds.), Principles and practice of stress management (2nd ed.). New York: Guilford. 1993. P. 333-372.

20. Fuller R.C. Carl Rogers, Religion, and the Role of Psychology in American Culture // J. Humanistic Psychology. 1982. № 22(4). P. 21-32.

21. Rolland, J.S., Walsh F. Family Therapy: Systems Approaches to Assessment and Treatment / In R.E. Hales, S. Yudofsky, J. Talbott (Eds.) American Psychiatric Press Textbook of Psychiatry. 2nd Edition. Philadelphia: American Psychiatric Press. 1994. P. 1097-1126.

22. Becvar D.S., Becvar R.J. Family therapy: A systemic integration. Boston, MA: Allyn \& Bacon, 1993. 400 p.

23. Nichols M. Family therapy: Concepts and methods. New York: Gardner Press, 1984. 609 p.

24. Husaini B.A., Sherkat D.E., Levine R. et al. Race, Gender, and Health Care Service Utilization and Costs among Medicare Elderly with Psychiatric Diagnoses // J Aging Health. 2002. № 14(1). P. 79-95.

25. Jeon H-S., Dunkle R.E. Stress and Depression Among the Oldest-Old: A Longitudinal Analysis // Research on Aging. 2009. № 31. P. 661-687.

26. Mair C.A. Social Ties and Depression: An Intersectional Examination of Black and White Community-Dwelling Older Adults // J. Applied Gerontology. 2010. № 29(6). P. 667-696.

27. Mills T.L., Henretta J.C. Racial, Ethnic, and Sociodemographic Differences in the Level of Psychosocial Distress among Older Americans // Research on Aging. 2001. № 23(2). P. 131-152. 
28. Paykel E.S. Life events, Social support and depression // Acta Psychiatrica Scandinavica. 1994. № 89(377). P. 50-58.

29. Ravindran A.V., Matheson K., Griffiths J. et al. Stress, coping, uplifts, and quality of life in subtypes of depression: a conceptual frame and emerging data // J. Affective Disorders. 2002. № 71(1-3). P. 121-130.

30. Sherbourne C.D., Hays R.D., Wells K.B. Personal and psychosocial risk factors for physical and mental health outcomes and course of depression among depressed patients // J. Consulting and Clinical Psychology. 1995. № 63(3). P. 345-355.

31. Dohrenwend B.P., Itzhak L., Shrout P. et al. Socioeconomic Status and Psychiatric Disorders: The Causation-Selection Issue // Science. 1992. № 255. P. 946-952.

32. Ensminger M.E. Welfare and Psychological Distress: A Longitudinal Study of African America Urban Mothers // J. Health and Social Behavior. 1995. № 36(4). P. 346-359.

33. Vostanis P., Grattan E., Cumella S., Winchester C. Psychosocial Functioning of Homeless Children // J. American Academy of Child \& Adolescent Psychiatry. 1997. № 36(7). P. 881-889.

34. Zima B.T., Bussing R., Freeman S. et al. Behavior Problems, Academic Skill Delays and School Failure Among School-Aged Children in Foster Care: Their Relationship to Placement Characteristics // J. Child and Family Studies. 2000. № 9(1). P. 87-103.

35. Blazer D.G., Landerman L.R., Hays J.C. et al. Symptoms of depression among community-dwelling elderly African-American and White older adults // Psychological Medicine. 1998. № 28(06). P. 1311-1320.

36. Culbertson F.M. Depression and Gender: An International Review // American Psychologist. 1997. № 52(1). P. $25-31$.

37. Kessler R.C., McGonagle K.A., Nelson C.B. et al. Sex and depression in the National Comorbidity Survey. II: Cohort effects // J. Affective Disorders. 1994. № 30. P. 15-26.

38. National Advisory Mental Health Council, 1996: Basic behavioral science research for mental health: perception, attention, learning, and memory // American Psychologist. 1996. № 51(2). P. 133-142.

39. National Advisory Mental Health Council. Basic behavioral science research for mental health: Sociocultural and environmental processes // American Psychologist. 1996. № 51. P. 722-731.

40. Scheid T.L., Brown T.N. A Handbook for the Study of Mental Health: Social Contexts, Theories, and Systems. 2-nd Edition University Cambridge University Press, 2009. 736 p.

41. Sue D.W. A conceptual model for cultural diversity training // J. Counseling \& Development. 1991. № 70. P. 99-105.

42. Sue D.W., Arredondo P., McDavis R.J. Multicultural Counseling Competencies and Standards: A Call to the Profession // J. Counseling \& Development. 1992. № 70. P. 477-486.

43. Porshnev B.F. O nachale chelovecheskoi istorii (Problemy paleopsikhologii). M.: Mysl', 1974. 487 s.

44. Bandura A. Teoriya sotsial'nogo naucheniya / Per. s angl. N.N. Chubar'. SPb.: Evraziya, 2000. 320 s.

45. Maslou A. Novye rubezhi chelovecheskoi prirody. M.: Smysl, 1999. $425 \mathrm{~s}$.

46. Krylov A.A. Psikhologiya: uchebnik / Pod red. A.A. Krylova, 2007. 752 s.

47. Ado A.D. i soavt. Patologicheskaya fiziologiya: Uchebnik dlya meditsinskikh VUZov / A.D. Ado, M.A. Ado, V.I. Pytskii, G.V. Poryadin, Yu.A. Vladimirov. M.: Triada-Kh, 2000. 607 s.

48. Bashina V.M. K probleme rannego detskogo autizma // Shizofreniya i rasstroistva shizofrenicheskogo spektra / Pod red. A.B. Smulevicha. M., 1999. S. 98-108.

49. Krasil'nikov G.T. Autizm i autisticheskii sindrom // Zhurn. nevropatol. psikhiatr. 1996. № 2. S. 105-110.

50. Khabib 0. Suitsidy sredi ugro-finnov // Russkii meditsinskii zhurnal. 1996. Tom 4. Vyp. 7. (URL: http://www.rmj.ru/ articles_3097.htm\#R5).

51. Polozhii B.S. Etno-i sotsiokul'tural'nye aspekty psikhicheskogo zdorov'ya v sovremennoi Rossii // Sbornik nauchnykh trudov «Kul'tural'nye i etnicheskie problemy psikhicheskogo zdorov'ya». M.-Izhevsk, 1996. Vyp. 1. S. 4-13.

52. Sokolova E.D. Sravnitel'noe psikhopatologicheskoe issledovanie v mezhregional'nom, transkul'tural'nom i mikrosotsial'nom aspektakh: Avtoref. diss. dokt. med. nauk. M., 1986. $43 \mathrm{~s}$.

53. Ambrumova A.G. Suitsidal'noe povedenie kak ob"ekt kompleksnogo izucheniya // Sbornik nauchnykh trudov «Kompleksnye issledovaniya v suitsidologi». M., 1986. S. 7-25.

54. Chukhraeva A.V.Psikhologicheskie osobennostibol'nykh s suitsidal'nymitendentsiyami // Ukrainskii vestnikpsikhonevrologii. 1996. Tom 4. № 1(8). S. 123-127.

55. Pchel'nikov Yu.M., Lazebnik A.I. Psikhologicheskoe issledovanie suitsidentov russkoi i udmurtskoi natsional'nosti // Istoriya Saburovoi dachi: Uspekhi psikhiatrii, nevrologii, neirokhirurgii i narkologii. Sbornik nauchnykh rabot Ukrainskogo NII klinicheskoi i eksperimental'noi nevrologii i psikhiatrii i Khar'kovskoi gorodskoi klinicheskoi psikhiatricheskoi bol'nitsy № 15 (Saburovoi dachi) / Pod obshch. red. I.I. Kut'ko i P.T. Petryuka. Khar'kov, 1996. Tom 3. S. 314-316. 